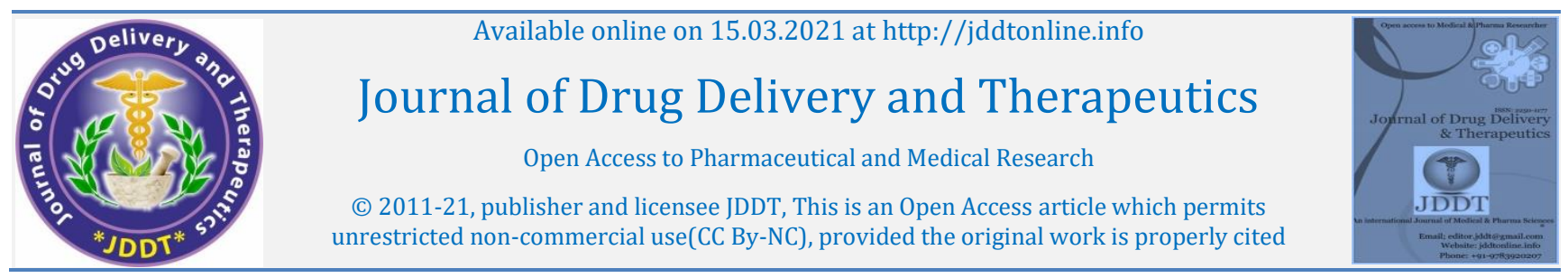

(C) 2011-21, publisher and licensee JDDT, This is an Open Access article which permits Open Access Full Text Article

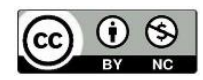

Review Article

\title{
A Review on Bio-Polymers Derived from Animal Sources with Special Reference to their Potential Applications
}

\author{
Das Biplajit ${ }^{1}$, Paul Sujata ${ }^{2}$ and Sharma Hemanta Kumar*2 (D) \\ ${ }^{1}$ School of Pharmaceutical Sciences, Shoolini University, Solan, Himachal Pradesh, India \\ ${ }^{2}$ Department of Pharmaceutical Sciences, Faculty of Science and Engineering, Dibrugarh University, Dibrugarh, Assam, India
}

\begin{tabular}{ll}
\hline Article Info: & \\
& Article History: \\
& Received 12 Jan 2021; \\
& Accepted 27 Feb 2021; \\
Available online 15 March 2021
\end{tabular}

Cite this article as:

Das B, Paul S, Sharma HK, A Review on BioPolymers Derived from Animal Sources with Special Reference to their Potential Applications, Journal of Drug Delivery and Therapeutics. 2021; 11(2):209-223

DOI: http://dx.doi.org/10.22270/jddt.v11i2.4763

\section{*Address for Correspondence:}

Dr. Hemanta Kumar Sharma, Department of Pharmaceutical Sciences, Dibrugarh University, Dibrugarh- 786004, Assam, India

\section{INTRODUCTION}

Polymers are the big molecules of high molecular weight called macromolecules, which are mainly formed by joining together a large number of tiny molecules, called monomers. The way through which monomers combine simultaneously to form polymer is known as polymerization. The term 'polymer' is derived from Greek words, polus which means 'many, much' and meros which means 'parts or units of big molecular masses'. Each molecule made up of a very broad fraction of single structural units combined together in a regular fashion by covalent bonds. ${ }^{1}$ The polymerization is called as a chemical reaction into which more than two materials join simultaneously with or without involvement of water, heat or solvents to produce a molecule of high molecular weight. The product which is attained is called polymer and the lead-off material from which the polymers are formed is named as monomer. ${ }^{2}$ Polymers may be either synthetic or natural in origin. Biopolymers are may be naturally found material and most of the materials made in nature during the life cycles of plants, animals, fungi and bacteria. Biopolymers are polysaccharides like cellulose, starch, the carbohydrate polymers yield by fungi and bacteria.

Animal protein-based biopolymers are wool, silk, collagen and gelatin biopolymers. Especially the carbohydrate origins are having very good industrial application in various forms. The polysaccharides listed below gives a brief layout on its biological source, pharmaceutical use etc. 3 For any pharmaceutical formulation the two main ingredients are active pharmaceutical ingredient and excipients. Excipients are pharmacologically inert ingredients formulated along with the active ingredient to increase the volume; they help in the formulating dosage form and also simultaneously can improve the physicochemical parameters of the dosage form.

As excipients in any kind of dosage form, the polymers play a vital function. The polymer used should be non-toxic, biocompatible, stable and economic etc and should control the release/release pattern of the drug. ${ }^{4}$ They are widely divided into three categories viz. natural polymers, semisynthetic and synthetic polymers. Natural polymers are used as stabilizing agents, rate-controlling agents, taste-masking agents and protective agents in the oral drug delivery system. To provide uniform delivery of drug some polymers are used. Moreover, polymers can minimize the frequency of dosing and can also raise the utility of the drug by localization at the site of action. Nowadays, due to many problems regarding the drug release and harmful effects of synthetic polymers, manufacturers are going towards using natural polymers. Natural polymers are polysaccharides, which is biocompatible and do not having any toxic effects. Applications of natural polymers in the pharmaceutical formulation are very much more as compared to the synthetic polymers and having vast scope in food and the cosmetic industry. ${ }^{5}$ Natural polymers and their derivatives are widely used in the development of new drug delivery system and this is because they are biodegradable, readily available, compatible with other ingredients and, and also having the ability for chemical modification. Natural polymers are given most preference because in case of 
synthetic excipients cause unwanted toxic effects and harmful effects in human and that's why researchers looking for the natural herbal constituents instead of synthetic or semi-synthetic polymers. Many studies showed that the release pattern of a drug from the formulation is affected by the physicochemical properties, morphology, and release pattern of the polymer along with the shape of dosage form and particle size. 6 The use of biopolymers in drug delivery systems was initially reported in the ' 80 s, but only in the 21st century, it is possible to observe an exponential increase in the research field.

Biopolymers illustrate an interesting substitute for synthetic polymers for use as structured carriers for controlled release of drug and drug encapsulation applications, such as biofilms and particles preparation. These carriers can hold both hydrophilic and hydrophobic drugs and also be applicable for many applications. Another advantage is the lack of chemical compounds and organic solvents employed to yield biopolymeric matrices which could be very fascinating for some industrial fields. For example, simple or complex coacervation methods containing proteins or protein and polysaccharide mixtures which are usually to create new matrices for controlled-release applications. The oral route of administration, which has been the most expedient and usually an efficient way of drug delivery for controlledrelease applications, has received the most attention. Determination of the hydration rate of polymers employed in sustained release applications has been an area of interest because it is taken into consideration that the hydration rate affects drug release from controlled-release matrix. Hydration time is the time required for a polymer to reach ultimate viscosity in a solvent. It has been proposed that rapid hydrating polymers are more pleasant because speedy gel development reduces the amount of drug initially released from a matrix and further prolong the period of release. 7 Polymeric nanoparticles have been widely investigated as pharmaceutical dosage forms because of their advantages, such as drug targeting, drug release control, improvement of the effectiveness of the drug, and reduce toxicity. Polymeric nanoparticles comprise nanospheres and nanocapsules. The previous are polymeric matrices while the after are vesicular carriers made up of oil in the core enclosed by a polymeric screen. Both of these colloids are stabilized by surfactants at the particle/water interface. Many methods are common for the preparation of polymeric nanoparticles using pre-formed polymers, such as nanoprecipitation and interfacial deposition, salting out, emulsification-evaporation, and emulsification-diffusion. The preparation of nanoparticles is also possible using the techniques of synthesis of biopolymers by methods such as suspension-polyaddition, interfacial polymerization, and mini-emulsion. The particle size distribution (polydispersity) and the mean particle size influence the drug release kinetics. Those features rely on proceeding factors and formulation criterion, for example, the stirring rate, the type and concentration of the stabilizers, the polymer concentration, and the technique employed in nanoparticles preparation. 8

Alignment of Natural Polymers ${ }^{9}$ - The specific appliance of natural polymers in pharmaceutical formulations are in the preparation of solid implants, films, beads, nanoparticles, microparticles, inhalation, viscous liquid formulations and also injectable systems as well. In these dosage forms, polymeric materials satisfied diverse roles such as matrix formers or drug release modifiers, stabilizers, binders, film coating formers, thickeners, solubilisers, gelling agents, suspending agents, disintegrants, emulsifiers and bioadhesives .10 One of the most important areas of research and development in drug delivery systems involves the development of controlled-release matrices, which may be defined as devices that deliver a therapeutic agent to a particular targeted site of the body and/or provide timely release of such an agent. Polymers are typically the material of choice for such utilization, given their diverse mechanical, physical, and chemical properties.

Polymers may be either synthetic or natural in origin. Those obtained from natural sources are generally referred to as biopolymers and include various macromolecules such as gelatin, polysaccharides, and cellulose, among others. For controlled-release matrices, such materials exist as hydrated networks named hydrogels, where the water content accounts for up to $-98 \%$ of the total mass. ${ }^{11}$

\section{TYPES OF POLYMER}

Natural polymers: Those are generally found in plant and animals sources. Examples are proteins, cellulose, silk, wool, starch, resins, chitin, etc. ${ }^{12}$

Semi-synthetic polymers: Those are obtained from natural polymers by simple chemical interference to switch the physical properties of natural polymers like Starch, silicones. 13

Synthetic polymers: Those are the fibers which are synthesized by polymerization of simple chemical molecules, example: Nylon, epoxy, polystyrene, polyethene, synthetic rubber, PVC, Teflon, etc. ${ }^{14}$

\section{CLASSIFICATION OF NATURAL POLYMERS}

Natural polymers are classified in three categories, such as:

(a) Plants origin,

(b) Animal's origin and

(c) Microbe's origin.

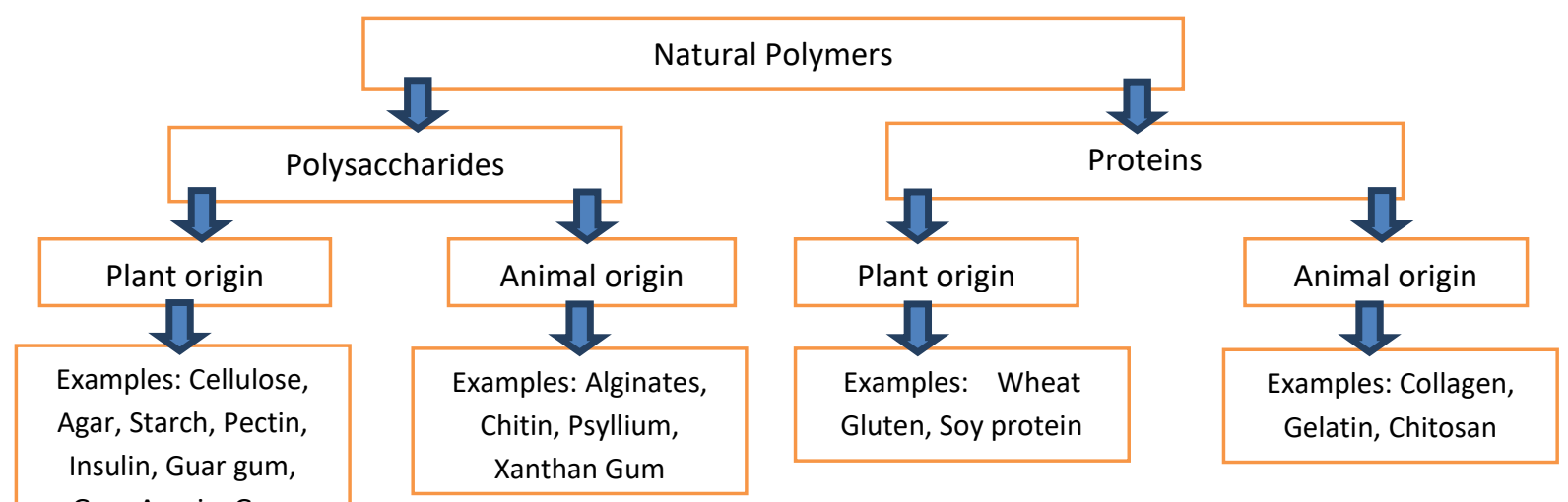

Figure 1: Classification of natural polymer 


\section{IMPORTANCE OF NATURAL POLYMERS (ANIMAL SOURCES) OVER SYNTHETIC POLYMER:}

The advantages of naturally occurring polymers over synthetic polymers are as follows:

- Biodegradable, biocompatible and non-toxic: Naturally occurring polymers yield by all living organisms. They do not show any toxic effects on human being. In opposite, synthetic polymers which is mainly prepared with the help of chemicals having toxic effects on the human being. 15 All of these plant materials are mainly carbohydrates in nature and made up of repeating monosaccharide units. Hence they are non-poisonous as compared to synthetic polymers. 16

- Economic: Natural polymers are accessible and they required less production cost as compared to the synthetic material. ${ }^{17}$

- Safe and devoid of side effects: They are found in a natural form and hence, safe and having no toxic effects, in where synthetic polymers made by using chemicals have adverse effects. 18

- Easy availability: Natural polymers are growing in the form of herbs in many countries. So it is very much economical than synthetic polymers and having no toxic effect and keeping in view their huge application in many industries, they are produced in large quantity hence their availability is ensured than synthetic polymers. 19

\section{DRAWBACKS OF NATURAL POLYMERS (ANIMAL SOURCES)}

These natural polymers also have some drawbacks, like -

- Microbial contamination: During preparation, they are manifested to outer environment hence there are possibility of microbial contamination. 20

- Batch to batch variation: Synthetic production is controlled process with fixed amounts of ingredients. While manufacturing of natural polymers is mainly rely on many biotic and abiotic parameters and environment. 21

- The uncontrolled rate of hydration: Due to variation in the collection of natural materials at several times and differences in species, climate conditions and regions, the percentage of chemical constituents present in a given material may vary. 22

- Slow Process: Natural polymers have a gradual rate of production and production rate is rely upon the environment and many other factors. 23

- Heavy metal contamination: There are chances of contamination of heavy metals often associated with herbal excipients. ${ }^{24}$

\section{BIOPOLYMERS FROM ANIMAL ORIGIN}

\section{CHITIN}

Source: Chitin is the polysaccharide derivative bearing amino and acetyl groups and plenty of organic constituent in the skeletal material of the invertebrates. Chitin, a naturally found biopolymer, containing 2-acetamido-2- deoxy-(1-4)-bD-glucopyranose residues ( $\mathrm{N}$-acetyl-D-glucosamine units) and mucopolysaccharide and dispersed in the shell of crustaceans, in the cuticle of insects, and in the cell wall of some fungi and microorganisms. ${ }^{5}$ It is mainly found in molluscs, annelids, arthropods. It is also a constituent of spores of many fungi and the mycelia. 25

Physicochemical properties: Chitin is highly basic polysaccharides; their properties include solubility in various media, solution, viscosity, polyelectrolyte behaviour, polyoxysalt formation, ability to form films, metal chelations, optical, and structural characteristics. ${ }^{26}$ Chitin is highly hydrophobic and is insoluble in water and most organic solvents. It is soluble in hexafluoroisopropanol, hexafluoroacetone, and chloroalcohols in conjunction with aqueous solutions of mineral acids and dimethylacetamide (DMAc) containing 5 per cent lithium chloride ( $\mathrm{LiCl}$ ). ${ }^{27}$

Composition: Depending on its source, chitin occurs as two allomorphs, namely $\alpha$ and $\beta$ forms. $\alpha$-Chitin isomorph is the most abundant. It is appeared in fungal and yeast cell walls, in krill, lobster and crab tendons and in shrimp shells and also in the insect cuticle. ${ }^{28}$ In addition to the native chitin, achitin is consistently formed by recrystallization from chitin solution by in vitro biosynthesis or enzymatic polymerization due to high thermodynamical stability of this isomorph. 29, 30 The rarer $\beta$-chitin is found in association with proteins in squid pens and in the tubes synthesized by pogonophoran and vestimetiferan worms. The crystallographic parameters of the two isomorphs allow us to conclude that there are two antiparallel molecules per unit cell in a-chitin but only one in ß-chitin in a parallel arrangement. In these two structures, the chains are build in sheets and taken by intra-sheet hydrogen bonds. In addition, in a-chitin, inter-sheet hydrogen bonds restrain diffusion of small molecules into the crystalline phase. ${ }^{31}$ No inter-sheet hydrogen bonds are found in the crystal structure of $ß$-chitin. This may explain its swelling in the appearance of polar guest molecules (ranging from water to alcohol and amines) which mainly penetrate the crystal lattice without disturbing the sheet organization and the crystallinity of the sample. The removal of the guest molecule allows us to revert to the original state of anhydrous $\beta$-chitin. The reactivity of $\beta$-chitin isomorph is larger than the a-chitin isomorph, which is important for enzymatic and chemical transformations of chitin. To conclude, both $\alpha$ and $\beta$ forms are insoluble in all the common solvents. This insolubility is a major drawback in case of the development of processing and applications of chitin. 32

\section{Structure:}

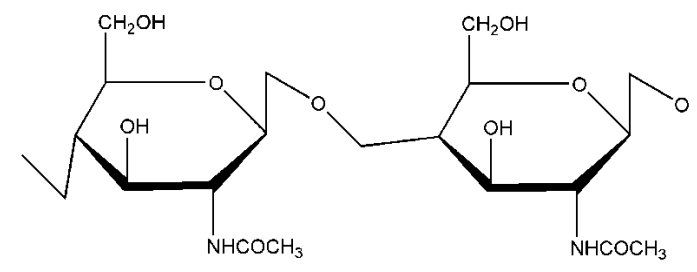

Figure 2: Chemical Structure of Chitin. ${ }^{6}$

Applications: Tissue engineering, Cosmetics, Wound Dressing, Stem cell technology etc. 33

\section{XANTHAN GUM}

Source: Xanthan gum is a natural high molecular weight polysaccharide, produced from the bacterium Xanthomonas campestris found on cabbage plants. 34

Physiochemical Properties: Xanthan gum powder is freeflowing white to cream coloured soluble in hot and cold water, but insoluble in most organic solvents. Xanthan gum solutions show a high viscosity as compare to other polysaccharide solutions at lower concentrations. 35 This property makes it more useful as stabilizer and thickener. Xanthan gum solutions are highly pseudoplastic but not 
thixotropic. 36 The pseudo-plasticity of xanthan gum increases sensory qualities in final products and ensures a good pourability. 37 Xanthan gum solutions are stable at various $\mathrm{pH}$ means they are adjustable in both acidic and basic conditions. In addition, xanthan gum has thermal stability that makes it more excellent to most other watersoluble polysaccharides. Xanthan gum is tasteless and does not affect the taste of other food ingredients. 38, 39, 40

\begin{tabular}{|l|l|}
\hline Property & Value \\
\hline Physical state & Dry, cream-coloured powder \\
\hline Ash (\%) & $7-12$ \\
\hline Nitrogen (\%) & $0.3-1.0$ \\
\hline Pyruvate content (\%) & $1.0-5.7$ \\
\hline Moisture (\%) & $8-15$ \\
\hline Divalent salt (g L-1) & $0.085-0.17$ \\
\hline Monovalent salt (g L-1) & $3.6-14.3$ \\
\hline Viscosity (cp) & $13-35$ \\
\hline
\end{tabular}

Composition: Xanthan gum is a high molecular weight polysaccharide produced by pure culture aerobic fermentation of carbohydrate with Xanthomonas campestris bacteria. It is a long-chained polysaccharide with a large number of trisaccharide side chains. The main chain consists of $ß$ - $(1,4)$-linked D-glucose units. The side chains are made up of one glucuronic acid unit and two mannose units attached with spare glucose residues of the main chain. The terminal D-mannose residues may carry a pyruvate function and the assignment of such a group in the chemical structure is subjected to the bacterial strain and the fermentation conditions. The non-terminal D-mannose unit in the side chain holds an acetyl function. ${ }^{41}, 42$ This polymer is having anionic property because of the existence of both pyruvic acid and glucuronic acid groups in the side chain. ${ }^{43}$ Xanthan gum has been widely observed as a possible polymeric material in diverse floating drug delivery technology in addition to being used as a gelling agent, stabilizing agent, suspending agent and viscosity increasing agent. For example, formulation and evaluation of rosiglitazone maleate, acyclovir, propranolol hydrochloride, and tapentadol-hydrochloride were done using xanthan gum. ${ }^{44}$

Applications: Xanthan gum is extensively applied in topical and oral formulations, cosmetics and in the food industry as a stabilizing and suspending agent. It has also been used to prepare sustained release matrix tablets. ${ }^{45}$

Structure:

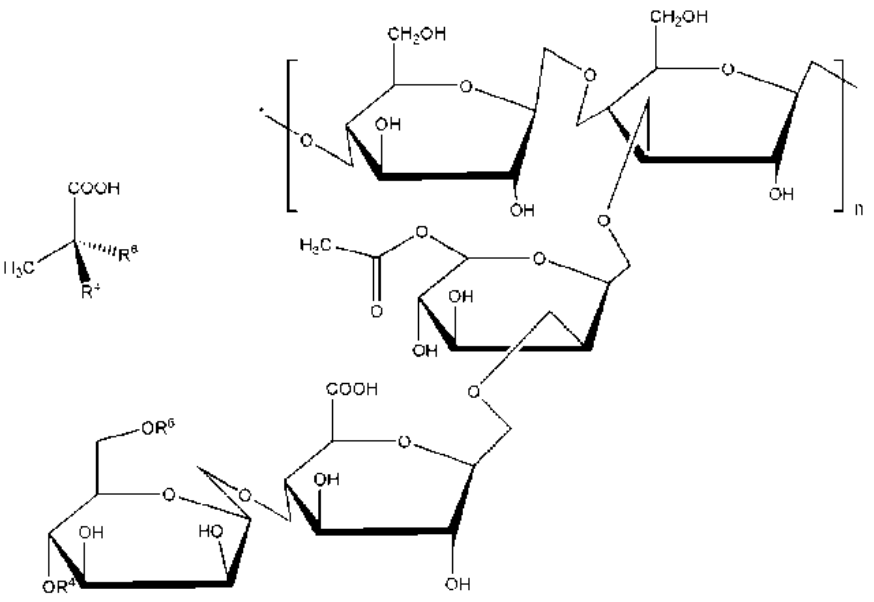

Figure 3: Chemical Structure of Xanthan

\section{COLLAGEN}

Source: Collagen is a naturally occurring protein present in the animal body, fibrous in nature, and especially found in the connective tissue and flesh of mammals. Approximately $25 \%-35 \%$ of total body protein comes under collagen, means in the form of extended fibrils; collagen is abundantly present in fibrous tissue like bone, cartilage, tendons, blood vessels, ligament, skin, cornea, intervertebral disc and the gut. 46 The collagen is synthesized in the body which is mainly done by fibroblast cells. Collagen shows good tensile strength and found in both inside and outside the body cells. In combination with elastic and collagen gives support to body tissues and organs, mainly elastic gives flexibility and collagen provides firmness and strength to body tissues ${ }^{47}$ In truth gelatin which is used in pharmaceutical and food industries is mainly collagen that has been hydrolyzed irreversibly. ${ }^{48}$
Physicochemical properties: The basic collagen molecule is rod-shaped with a length and a width of about 3000 and $15 \mathrm{~A}$, respectively, and has an approximate molecular weight of $300 \mathrm{kDa} .{ }^{49}$ It has high tensile strength and high affinity with water. 50,51

Composition: 27 types of collagen exist and composed of different polypeptides, which contain mostly glycine, proline, hydroxyproline and lysine. The elasticity of the collagen chain relies on the glycine content. 52 Basically, collagen shows a triple helix structure, which is generally composed of one supplementary chain and two homologous chains (a-1) that varies slightly in its chemical composition (a-2). These chains are polypeptide in nature and coiled are around one another in a cable form. Each has a distinct turn in the reverse direction; these chains are joined together by hydrogen bonds between nearby $\mathrm{NH}$ and $\mathrm{CO}$ groups. 53 The weight of the collagen molecule is $300 \mathrm{k} \mathrm{da}$ and its structure is rope shaped and having a length of $300 \mathrm{~nm}$ and a width of 
$1.5 \mathrm{~nm}$. The major quantity of glycine and the amino acid residue is showing it's an effect in the helix formation in each of three chains of collagen molecule the amino acids are regularly arranged. The sequence of amino acids maintain the pattern glycine-X-hydroxyproline or glycine-proline-X, where $\mathrm{X}$ is the amino acid other than proline or hydroxyproline and glycine; proline or hydroxyproline accounting for the $1 / 6$ of the sequence and glycines constitute about $1 / 3$ of the total sequence. This whole structure is joined with the help of hydrogen bonds and linking peptide bonds. 54

\section{Structure:}<smiles>[R3]C(NC(=O)C1CCCN1C(=O)CNC(C)=O)C(=O)N([2H])[C@@H]([2H])C(=O)N[C@@H]([R2])C(=O)N1C[C@@H](O)C[C@H]1C(=O)N(C)C</smiles>

Figure 4(A): Type-1 Collagen<smiles>CCC(C)C(NC(=O)CNC(=O)C1CCCN1C(=O)C1CC1(NC(=O)CN)NC(=O)CCCCN)C(=O)NC(C)C(=O)NCC(=O)NC(Cc1ccccc1)C(=O)NC(CCCCN)C(=O)NCC(=O)NC(CCC(=O)O)C(=O)NC(CCC(N)=O)C(=O)NCC(=O)N1CCCC1C(=O)NC(CCCCN)C(=O)O</smiles>

Figure 4(B): Type-2 Collagen

\section{Application:}

Ophthalmology: Collagen films are used in ophthalmology as drug delivery systems for slow release of incorporated drugs. 55

Tissue engineering/microsphere: It was used for tissue engineering including skin replacement, valves, bone substitute and artificial blood vessels. 56, 57 Used in the formation of microspheres for drug delivery and the formulation of nanoparticles for gene delivery. ${ }^{58}$ Collagen is used in the production of collagen Sponges for burns or wounds. ${ }^{59}$ They are also used in development of pellets and tablets for the delivery of proteins. ${ }^{60}$ For sustained delivery of drugs, collagen is used for gel formulation and combined with liposomes. In the treatment of cancer, collagen is used as an aqueous injection. Collagen is used as a collagen shield in ophthalmology. Collagen is used for the controlling of drug release from transdermal patches. ${ }^{61}$ For the delivery of glucocorticosteroids, microparticles of collagen are used. 62
Nanoparticles/nanospheres - The nanoparticles or nanospheres based biodegradable collagen are thermally stable, readily achieve their sterilization. Because of its small size, a large surface area, high adsorptive capacity and ability to disperse in water to form a clear colloidal solution, collagen-based nanoparticles have demonstrated their potential to be used as a sustained release formulation for anti-microbial agents or steroids. ${ }^{63}$ Nanoparticles have been used as a parenteral carrier for cytotoxic agents and other therapeutic compounds, such as camptothecin ${ }^{64}$ and hydrocortisone. 65

Collagen sponges - Collagen sponges are very useful in the management of severe burns and as a dressing for severe types of wounds. Collagen dressings are prepared in a variety of different forms including, sponges, membrane sheets and powder, having essential biological properties important for such application. ${ }^{66}$ 


\section{GELATIN}

Sources: It is a water-soluble polypeptide that can be acquired from acid, base or enzymatic hydrolysis of collagen, the main protein component of the skin, bones and connective tissue of animals, including fish and insects. 67 Gelatin obtained by acid treatment, like hydrochloric acid or sulfuric acid, which is known as type A, whereas gelatin obtained by an alkaline treatment is known as type B. After both types of treatments, the solutions are filtered, deionized and concentrated by or vacuum evaporation and membrane filtration method. Minerals, fats and albuminoids present in bones or skin which are then dispelled by physical and chemical treatment for obtaining purified gelatin. Gelatin which is obtained from porcine skin is a popular source (46\%), followed by bovine skin (29.4\%), bone $(23.1 \%)$ and other sources $(1.5 \%)$. The other sources of gelatin are poultry, vertebrates, fish and even recombinant gelatin. 68

Physicochemical properties: Gelatin is nearly tasteless and odourless. It is a vitreous, brittle solid faintly yellow in colour. Gelatin contains 8-13\% moisture and has a relative density of 1.3-1.4. When gelatin granules are soaked in cold water they hydrate into discrete, swollen particles. On being warmed, these swollen particles dissolve to form a solution.
Gelatin is soluble in aqueous solutions of polyhydric alcohols such as glycerol and propylene glycol. Examples of highly polar, hydrogen-bonding, organic solvents in which gelatin will dissolve are acetic acid, trifluoroethanol, and formamide. Gelatin is insoluble in less polar organic solvents such as benzene, acetone, primary alcohols and dimethylformamide. Gelatin stored in air-tight containers at room temperature remains unchanged for long periods of time. When dry gelatin is heated above $45^{\circ} \mathrm{C}$ in the air at relatively high humidity (above 60\% RH) it gradually loses its ability to swell and dissolve. Two of gelatin's most useful properties, gel strength and viscosity, are gradually weakened on prolonged heating in the solution above approximately $40^{\circ} \mathrm{C}$. Degradation may also be brought about by extremes of $\mathrm{pH}$ and by proteolytic enzymes including those which may result from the presence of microorganisms. Gelatin, in terms of basic elements is composed of $50.5 \%$ carbon, $6.8 \%$ hydrogen, $17 \%$ nitrogen and $25.2 \%$ oxygen. 69

Composition: Gelatin is a proteinaceous substance which is water-soluble and made by the destruction of the secondary, tertiary and primary structure of native collagens. Gelatin is different from other hydrocolloids. Because most of them are polysaccharide, but gelatin is a digestible protein carry out all the necessary amino acids besides tryptophan. 70

\section{Structure:}

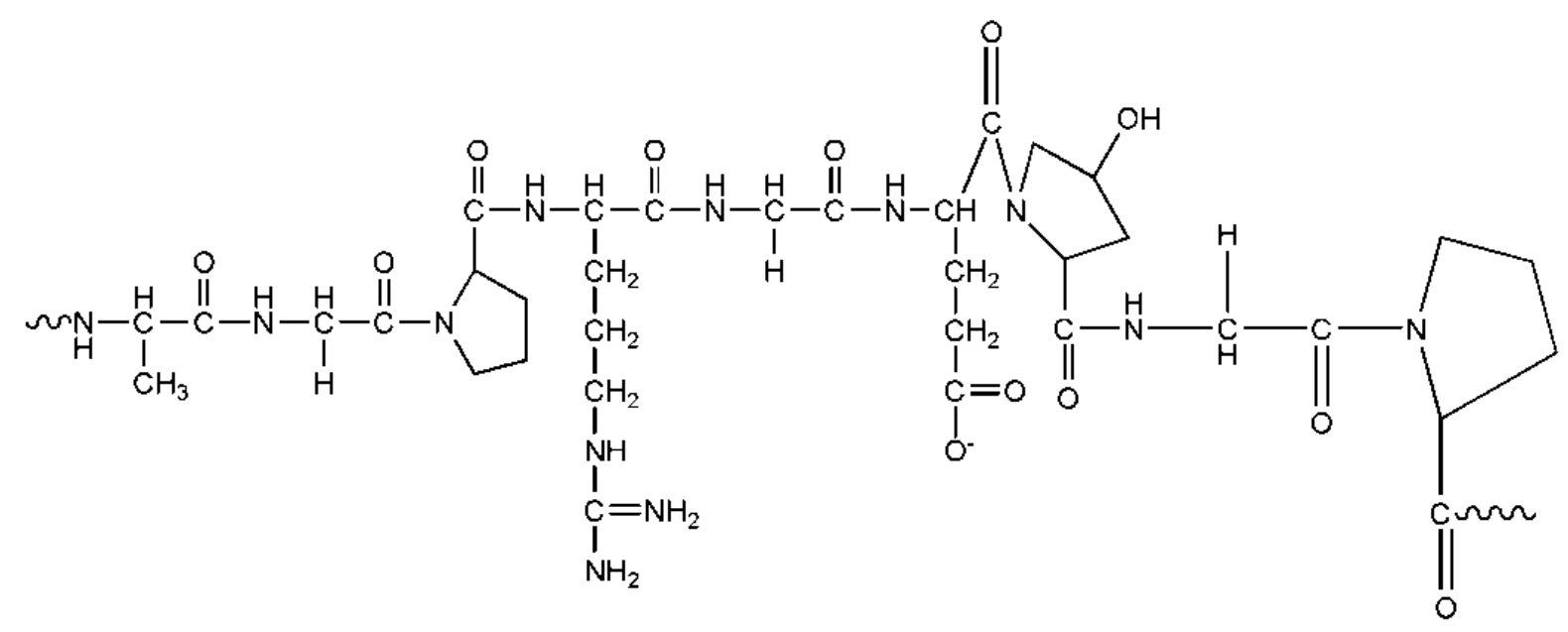

Figure 5: Chemical Structure of Gelatin

\section{Application:}

Tablet Coating - Tablets are generally coated to reduce dusting, mask unpleasant taste, and allow for printing and colour coatings for product identification. The coating process is more and more becoming aqueous-based which allows for the use of gelatin. Typical formulations for coating include a sugar, pigment, and gelatin to act as a film former. The most popular coating method utilizes a roll coating pan and the addition of the coating solution as a fine spray. ${ }^{71}$

Microencapsulation - Gelatin is used to produce microencapsulated oils for various uses both in nutritional and pharmaceutical applications. The traditional method of encapsulation is known as coacervation in which the dispersed oil is encapsulated by gelatin at the interface between the aqueous phase and the nonaqueous phases. Common examples of this are vitamin supplements for various foods and for multi-vitamins. The size and formation of the spherical microcapsules can be controlled by various methods. Typical microcapsules range in size from 5 microns to 500 microns. ${ }^{72}$
Plasmas Substitutes - Solution of modified gelatin (3.0 $5.5 \%$ ) and salts are commonly used as plasma substitute during emergency surgery. ${ }^{73}$

\section{CHITOSAN}

Source: Chitosan is also a natural cationic polymer derived by deacetylation of chitin under alkaline conditions. ${ }^{74}$

Physicochemical properties: Chitosan is water-soluble compound and its molecular weight is $50-200 \mathrm{kDa}$. Chemically chitosan is linearpolymine, possess reactive amino groups, hydroxyl and can chelates many transitional metal ions.

Composition: Chitosan is a linear polysaccharide. It contains 2-amino-2-deoxy-(1-4)-b-D-glucopyranose residues (Dglucosamine units). ${ }^{15}$ Because of the deacetylation of chitin, chitosan can be liquefied in water by the formation of salt with different acids on the amino group of D-glucosamine units. Further, chitosan has partially acetylated 50\% Dglucosamine units therefore; it is miscible in water alone. 75 


\section{Structure:}

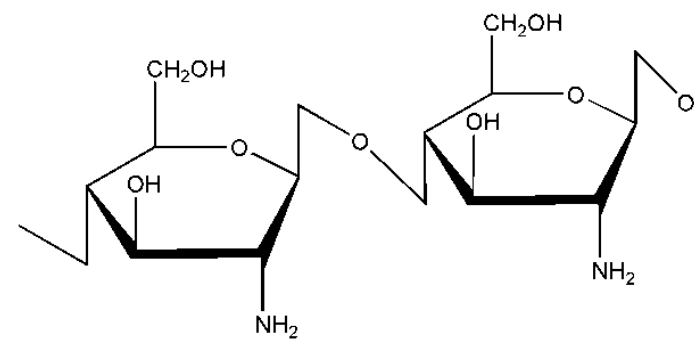

Figure 6: Chemical structure of Chitosan 6

Application: Chitosan and their derivatives (N-trimethyl chitosan, mono-N-carboxymethyl chitosan) are used as safe and effective absorption enhancers to promote nasal, mucosal drug delivery, peroral drug delivery of hydrophilic macromolecules such as peptide and proteinous drugs. Chitosan nanoparticles and microparticles are also suitable for controlled drug release. 76

\section{DEXTRAN}

Source: They are obtained from bacterial cultures of Leuconostoc mesenteroides and represent the second group of biopolymers most studied in drug delivery with $17 \%$ of publications. These glycosidic linkages are hydrolysed by bacteria, moulds and mammalian cells. 77
Physicochemical properties: Dextran is readily soluble in water, dimethyl sulfoxide, formamide, ethylene glycol, and glycerol but insoluble in monohydric alcohols, e.g., methanol, ethanol, and isopropanol, and also most ketones, e.g. acetone and 2- propanone. dextrans have high water solubility, and the aqueous solutions behave as Newtonian fluids. However, some branched dextrans showed shear rate thinning effect, exhibiting non-Newtonian pseudoplastic behaviour. The viscosity of the dextran solution depends on its concentration, temperature, and molecular weight. As dextran is a neutral polysaccharide, the viscosity is not significantly influenced by changes in $\mathrm{pH}$ or salt concentration. Dextrans with $>43 \%$ branchingthrough $\alpha-$ (13) linkages are water-insoluble. Dextrans have molecular weight in the range of 3-500,000 $\mathrm{kDa}$. Dextrans with a molecular weight of $2,000-10,000 \mathrm{kDa}$ exhibit the properties of an expandable coil, and at lower molecular weights $(<2,000 \mathrm{kDa})$, dextran is more rodlike. ${ }^{78}$

Composition: Dextrans are a class of polysaccharides with having linear polymer backbone of 1, 6-D-glucopyranosidic linkages. Dextranases are the enzymes which hydrolyse these glycosidic linkages. Several drug-dextran prodrugs in where mainly drug molecule is attached to the polar dextran macromolecule keep intact in the stomach and small intestine and are absorbed from there, but when the prodrug drives into the colonic microflora containing Bacteroides it is acted upon by dextranases which cleave the dextran chain randomly and at the terminal linkages, releasing the drug freely into the colon. 79

\section{Structure:}

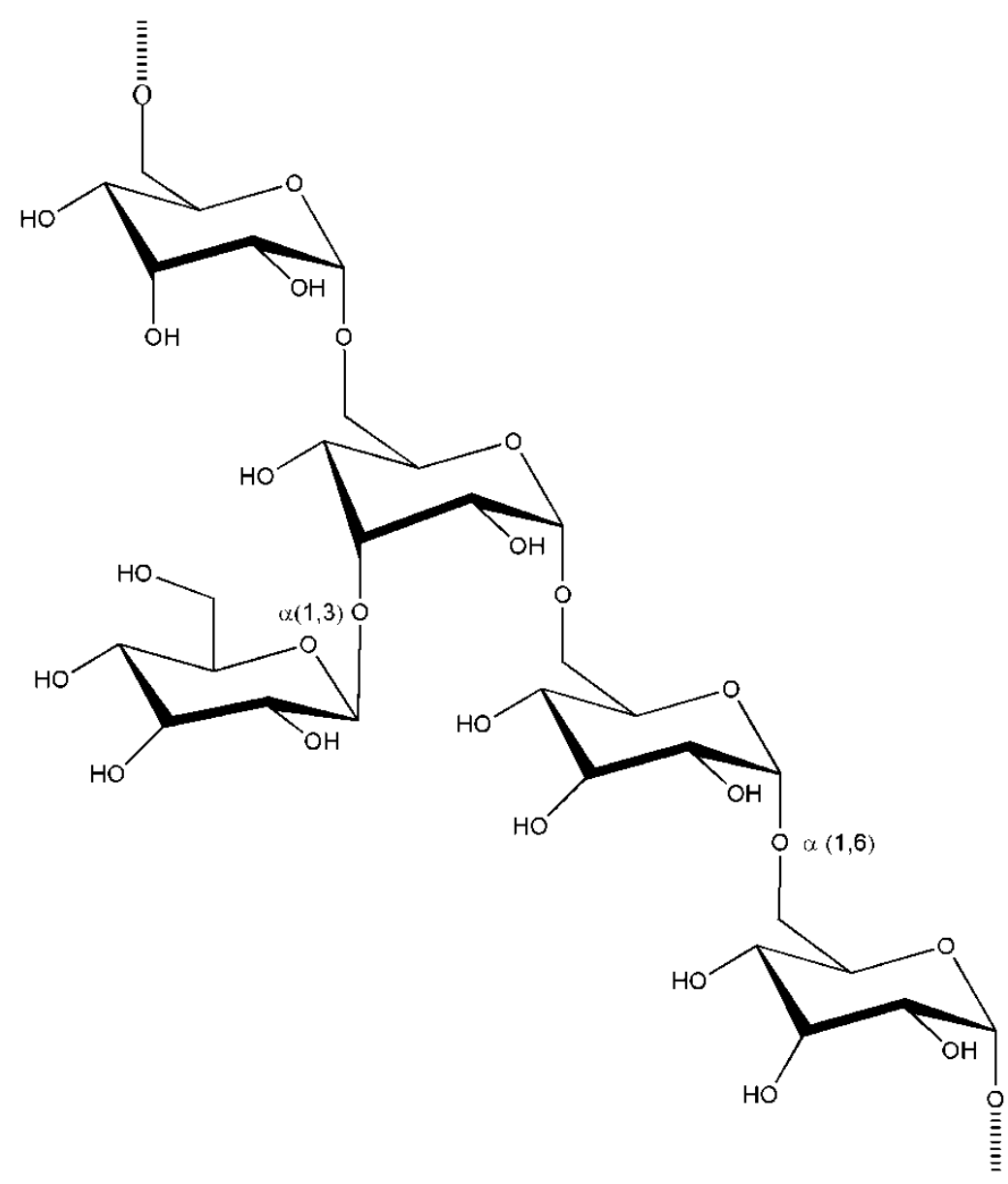

Figure 7: Chemical Structure of Dextran 


\section{Application:}

In the field of cosmetics - Dextran and Dextran derivatives have some beneficial applications to the cosmetics as a moisturizer and a thickener, especially Cationic Dextran (CDC) makes complex salts with anionic or amphoteric surfactants, which moderately adsorb to hair and skin to form films having moisturizing effects. CDC is a useful conditioning agent for hair care and skincare products. Dextran sulfate has the following properties which make it more favourable for its usage in cosmetics (Anti-ageing, Anti-wrinkle effects, Smooth fresh, Anti-inflammatory and anti-allergic, Treating rough, chapped skin). Dextran sulfate has been found to reduce lymphoblast extravasation in skin sites inflamed. The osmotic retention of water by Dextran sulfate present in the tissue will contribute to the well-being and mechanical properties of the tissue concerned. 80,81

Antithrombotic effect - These agents are used to decrease vascular thrombosis. The antithrombotic effect of dextran is mediated by its binding of erythrocytes, endothelium, increasing their platelets and vascular electronegativity and thus reducing erythrocytes aggregation and platelet adhesiveness. Dextran also reduces the VIII-Ag Von Willebrand factor, thereby decreasing platelet function. 82

\section{GENERAL MECHANISM OF DRUG RELEASE FROM POLYMER}

There are three main mechanisms through which active drugs can be released from a delivery system namely.

- Diffusion: Diffusion takes place when a drug going through the polymer and then it made the controlledrelease device. Diffusion takes place when the drug passes from the polymer matrix into the outer environment. As these type of systems are required to travel longer distance so the diffusion rate of the bioactive agent should be controlled. The combinations of the bioactive agent and polymer matrices should be such that it does not cause any change to the polymer but allows the bioactive agent to diffuse through the macromolecular structure or pores of the polymer as when introduced into the biological. 83

- Degradation: Biodegradable polymers overcome the need of removal of the polymer from the body after completion of release of the bioactive agent from the system because the polymers get degraded inside the body due to some natural biological processes. Most of the biodegradable polymers get degraded into biologically acceptable and gradually smaller compounds as a result of hydrolysis of the polymer chains. Again in some degradable polymers (polyanhyrides and polyorthoesters), degradation occurs only at the surface of it which makes the release rate proportional to the surface area of the drug delivery system. ${ }^{84}$

- Swelling: The dry system when placed within the body, the polymer present there absorbed water or body fluids and swell. Due to swelling the fluid content increases in the system which allows the bioactive agent to diffuse through the swollen polymer mesh. 85

\section{GENERAL PRODUCTION OF BIOPOLYMERS}

Biopolymers are used in various fields which are produced by a different number of ways:

(i) A large number of biopolymers are present in nature and are extracted mostly from plants and algae. Biopolymers like agar and alginates are isolated from red algae which belong to the genus Gelidium or from various brown algae also known as seaweeds.

(ii) Some biopolymers are isolated from exceptionally natural sources. Hyaluronic acid which is isolated from the umbilical cords of a newborn is an example of such type of biopolymer.

(iii) Biopolymers can also be produced by in vitro synthesis method in which the biopolymers were produced by treating with isolated enzymes in cell-free systems. Such one example is the application of the heat-stable DNA polymerases in the polymerase chain reaction (PCR) to produce monodisperse defined DNA molecules. Another example is the production of dextran with isolated dextran sucrose, on a technical scale. 86

(iv) Production of biopolymers by fermentation is generally used in the industry also known as biotechnological production, for e. g. production of polysaccharides. This process may occur both intracellularly or extracellularly that causes several limitations of production of biopolymers in the pure state. 87

Intracellular versus extracellular production of biopolymers:

Examples of biopolymers that accumulated in the cytoplasm of the cells, as a result, intracellular synthesis are cyanophycin, glycogen, polyhydroxyalkanoates, polyphosphate and starch. But the confined space in the cytoplasm limits the amount of production of the polymer by a cell. This fermentation process is particular employed by microorganisms and so, the product obtained per volume is determined by the cell density and the fraction of biopolymer in the biomass.

Examples of biopolymers that occur outside the cell due to extracellular synthesis or of excretion by the cells are Poly ( $ß-D$ glutamate) and many polysaccharides, such as alginates, chitosan, curdlan, dextran, xanthan, pullulan and microbial cellulose. This process can produce the desired amount of biopolymer without breakage of the cells and the separation process from the biomass is easy too. For these biopolymers, the volume of the bioreactor would be available to deposit the desired biopolymer. One more strategy to give rise to biopolymers by fermentation process is to produce the constituents of polymers as monomers and then subsequently polymerize these components by chemical processes only. This process is a combination of biotechnological and chemical approach. Polylactic acid, for example, has been produced on a large scale by such a combined. 88

Genetic engineering and biopolymer technology: Modern biotechnology act as the revolutionary tools for scientists to probe and manipulate living systems. And genetic engineering provides extraordinary power to control the time, place, level, and type of 'gene expression'. For example, protein polymers; accessing the genetic blueprint (gene) of the protein polymer, the system that formed the polymer and the composition of the polymer can be changed. Recombinant DNA techniques allow the genesis of polymer chains that are basically rigid in length, composition, and stereochemistry or spatial orientation. Genetically engineered biopolymer production systems: The products obtained by this system are regulated not by the manufacturing process but on the basis of their application. Under ongoing Food and Drug Administration (FDA) rules, genetically engineered foods are considered the same way as conventional products. The FDA does not require that new products be approved or labelled, as long as such products are essentially similar in composition, structure, and function to food items already available on the market. However, the U.S. Department of Agriculture and 
Environmental Protection Agency (EPA) do control the field tests of genetically modified plants. And till now for the field testing of genetically altered plants and other organisms, more than 700 permits have been granted. 89

\section{METHOD OF PREPARATION OF BIOPOLYMERS \\ GELATIN}

Isolation and Purification of Collagen:

Although the body of mammals retains a large amount of collagen and skin, tendons are the tissues that are rich in fibrous which contain collagen. They are the starting materials to yield collagen for use in transplantation, drug delivery systems, or wound dressings. Different sources of bovine, procaine and sheep collagen includes human placenta, marine sources, and recombinant human collagen from transgenic animals. Autologous collagen material is used for building of surgical sutures as an alternative of the gut mucosa. Generally, collagen is insoluble in organic solvents and the water-soluble part of the collagen contribute to an only small fraction of the total collagen which depends on the types of tissue isolated and age of the animal. In case of young animals at suitable conditions, only a small amount of collagen can be extracted due to less cross-linking capacity of their skin, but the collagen present within the fibril masses can be parted and carried to the aqueous solution. For different tissues, specific solvents are used which depend on the nature of the cross-linking capacity. In pharmaceutical industries generally, four types of collagen can be extracted and purified for drug delivery purpose. ${ }^{90}$ They are -

(a) Natural salt soluble collagen

(b) Alkali and enzyme treated collagen

(c) Acid soluble collagen

(d) Insoluble collagen

The process to Isolate Neutral Salt Soluble Collagen is shown in Figure 8.

Tissue containing slightly cross-linked collagen is taken

Extracted with neutral salt solution $(0.15-2 \mathrm{M} \mathrm{NaCl}) /$ dil acetic acid

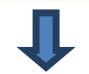

Adjusting and maintaining the process variable viz. temperature, shaking, rate and $\mathrm{pH}$

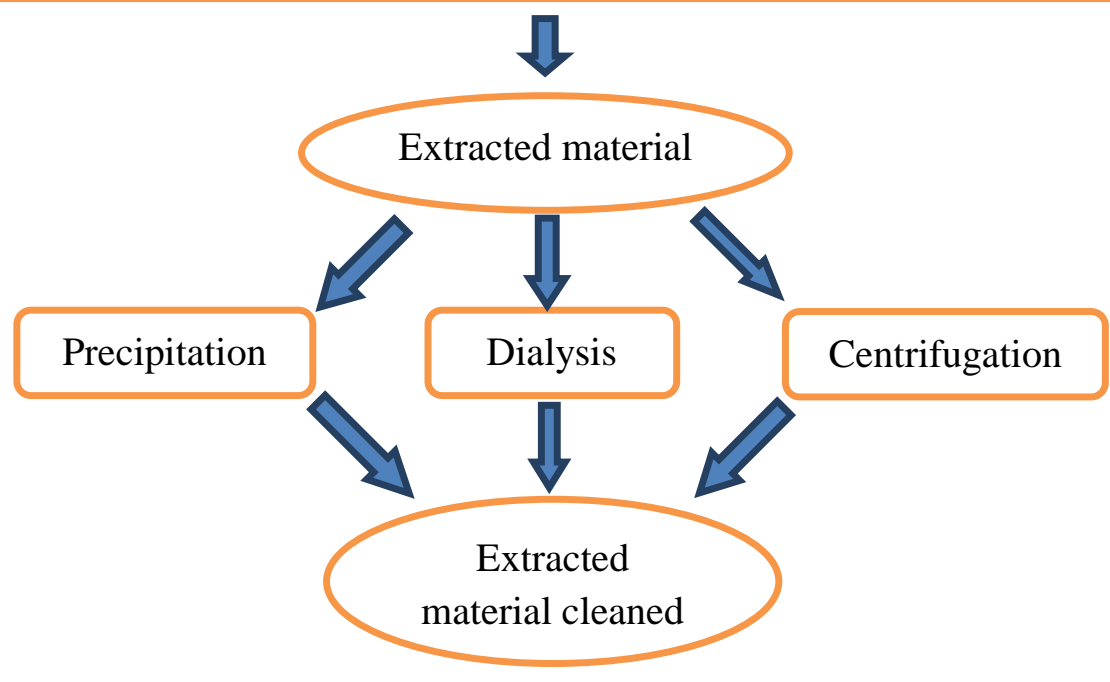

Figure 8: Process to isolate neutral salt soluble collagen 
The process to extract Collagen which are acid soluble is shown in figure 9.

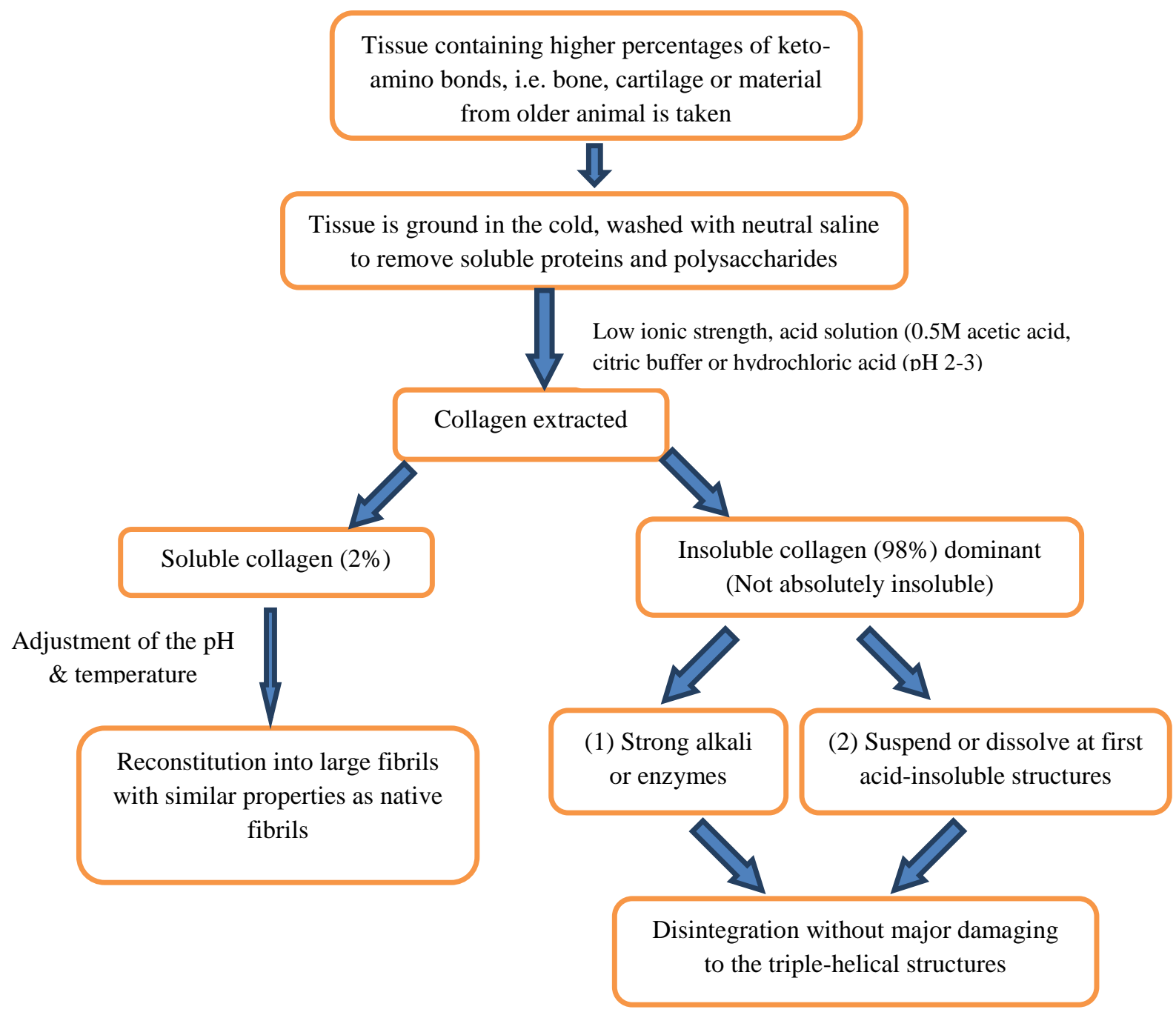

Figure 9: Process to isolate acid-soluble collagen

The process to isolate alkali- and enzyme-treated collagen is shown in figure 10. ${ }^{91}$

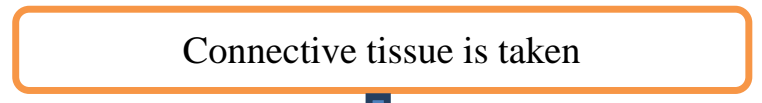

Treated with an aqueous solution of alkali hydroxide and alkali sulphate (that controls the swelling of the collagen structures and protects the native triple-helical characteristics

Approximately $10 \%$ sodium hydroxide and $10 \%$ sodium sulphate for 48 hours

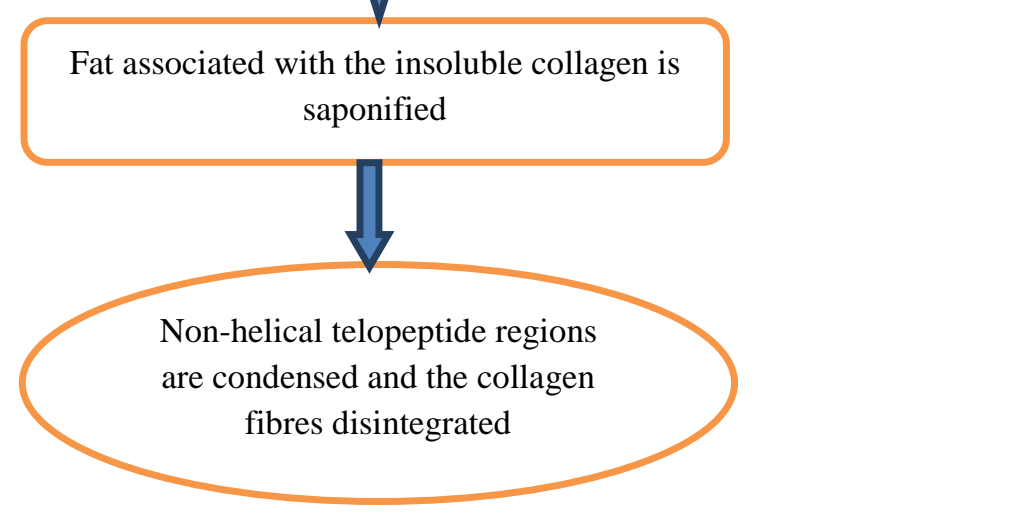

Figure 10: Process to isolate alkali and enzyme-treated collagen 


\section{XANTHAN GUM}

The biosynthesis of xanthan, a microbial heteropolysaccharide, is a much complex process, which involves a multi-enzyme system. The first step in the biosynthesis of xanthan is to take up carbohydrate which may be occurred by active transport or facilitated diffusion, followed by phosphorylation of the substrate with a hexokinase enzyme that utilizes adenosine 5'-triphosphate. This biosynthesis involves the conversion of the phosphorylated substrate to the various sugar nucleotides required for assembly of the polysaccharide repeating unit through enzymes such as UDP-Glcpyrophosphorylase. For the synthesis of xanthan, UDP-glucose, GDPmannose and UDP-glucuronic acids with the appropriate repeating unit are required for the synthesis of xanthan. From cabbage plant, xanthan gum can be biosynthesized by Xanthomonascampestris, here carbohydrates substrates, proteins and minerals are contributed by the cabbage for the cell growth. In the laboratory conditions or industrial fermentation, carbon sources, nitrogen sources, trace minerals and $\mathrm{pH}$ conditions are provided similar to natural conditions. ${ }^{92}$

\section{CHITIN}

Chitin Extraction: Cuticles of diverse crustaceans, predominantly crabs and shrimps serve the primary sources of raw material for the yield of chitin. Chitin is found in crustaceans especially shellfish as an ingredient of an entangled network with proteins which form a rigid shell due to deposition of calcium carbonate. In the complex chitin and protein interacts very closely and a small fraction of protein is also responsible for the polysaccharide-protein complex. So, to isolate chitin from shellfish, removal of calcium carbonate by demineralization and proteins by deproteinization along with other trace pigments and lipids are compelling. To remove residual pigments an additional step, decolourization can be employed. For the preparation of pure chitin, various methods have been recommended and used through the years; although, no standard method has been approved till now. Using enzymatic or chemical treatments, demineralization of calcium carbonate and deproteinization of proteins could be carried out. Microbial fermentation can also be employed simultaneously. ${ }^{93}$ The type of shells possess by the crustaceans are also need to consider for the treatment process. Preferably, same species and same sizes of shells are selected. For example, in the case of lobsters and crabs, based on the quality of the final extracted material the selection is done. Chitin isolation is easier in case of shrimps than from other types of shells as the wall of shrimp's shell is thinner. ${ }^{94}$

\section{Chemical Extraction}

- Chemical Deproteinization: The bonds between chitin and proteins get easily disrupted so the deproteinization step is difficult. It is performed with the aid of chemicals which can also depolymerize the biopolymer. Some humans are allergic to shellfish mainly due to the presence of protein. So, for biomedical application complete removal of protein is mandatory. The first approach used for deproteinization is chemical methods. The deproteinization reagents includes $\mathrm{Ca}(\mathrm{OH})_{2}, \mathrm{CaHSO}_{3}$ $\mathrm{KOH}, \mathrm{K}_{2} \mathrm{CO}_{3}, \mathrm{Na}_{2} \mathrm{SO}_{3}, \mathrm{NaHSO}_{3}, \mathrm{Na}_{3} \mathrm{PO}_{4}, \mathrm{NaOH}, \mathrm{Na}_{2} \mathrm{CO}_{3}$, $\mathrm{NaHCO}_{3}$ and $\mathrm{Na}_{2} \mathrm{~S}$. In each study, the reactions conditions vary considerably. Among the above-mentioned deproteinization reagents, $\mathrm{NaOH}$ is the mostly used with treatment period ranges from few minutes to few days and used at concentration ranges from 0.125 to $5.0 \mathrm{M}$, at temperature up to $160^{\circ} \mathrm{C}$. Apart from deproteinization, the utilization of $\mathrm{NaOH}$ results in hydrolysis of the biopolymer which lowers its molecular weight and also partial deacetylation of chitin. 95

- Chemical Demineralization: By demineralization process mainly the mineral, calcium carbonate is removed. Demineralization is usually carried out by acid treatment using acids like $\mathrm{HCl}, \mathrm{HNO}_{3}, \mathrm{H}_{2} \mathrm{SO}_{4}, \mathrm{HCOOH}$ and $\mathrm{CH}_{3} \mathrm{COOH}$. Between those acids, dilute hydrochloric acid is mostly preferred because it decomposes calcium carbonate into water-soluble calcium salts along with the discharge of carbon dioxide which is given in the following equation.

$2 \mathrm{HCl}+\mathrm{CaCO}_{3} \longrightarrow \mathrm{CaCl}_{2}+\mathrm{H}_{2} \mathrm{O}+\mathrm{CO}_{2} \uparrow$

Similarly, the additional minerals present in the cuticle of shellfish react with acid and form soluble salts. Those salts can smoothly separate out the chitin solid phase by filtration accompanied by washing with the aid of deionized water. Demineralization treatments are seldom empiric and alter with the degree of mineralization of each shell, acid concentration, temperature, solute/solvent ratio, particle size, and extraction time. Due to heterogeneity of the solid, concentrated and large volume of the acid solution is problematic to get rid of all the minerals. The acid concentration should be equal or even greater to the stoichiometric amount of the minerals; as two molecules of $\mathrm{HCl}$ is required to transform one molecule of calcium carbonate into calcium chloride. Demineralization can be accompanied by acidimetric titration: where the retention of acidity in the medium reveals that the reaction is ended and neutralization of the medium reveals total consumption of the acid. 96

Exemptions to the aforementioned method are seen in the methods of Horowitz et al. and Synowiecki et al. where with $90 \%$ formic acid and $22 \% \mathrm{HCl}$, respectively, demineralization is done. Above all methods include forceful treatments that could possibly lead to modifications of the native chitin, like depolymerization and deacetylation. So to overcome these problems some alternative methods have been established by the use of mild acids. As for example, Austin et al. used ethylenediaminetetracetic acid (EDTA), Brine and Austin used acetic acid, Peniston and Johnson applied the sulfurous acid process replacing those strong acids. But these treatments process produced chitins with a high amount of ash content as residue. To demineralize $\mathrm{HCl}$ can be added in under stirring conditions. However, with the preparation methods, the reaction time vary from $15 \mathrm{~min}$ to 48 has shown in Table 1. Longer the demineralization time (up to several days) lesser will be the ash content but it leads to degradation of the polymer. Also, it was reported that the demineralization reaction can be fasten using a high temperature that promotes the penetration of the solvent into the chitin matrix. So, at a higher temperature, most of the demineralization reactions were carried out. Furthermore, it was reported that the particles size is also responsible for the penetration of the solvent into the chitin matrix. Conforming to Marquis-Duval, demineralization is the determining element for the contact area between the solvent and the chitin matrix. Nonetheless, it was also reported that high temperatures, longer incubations, high acid concentrations and granulometry distrub the final physicochemical properties of the developing chitin. 97 Preparation of Chitin is shown in figure 9. 


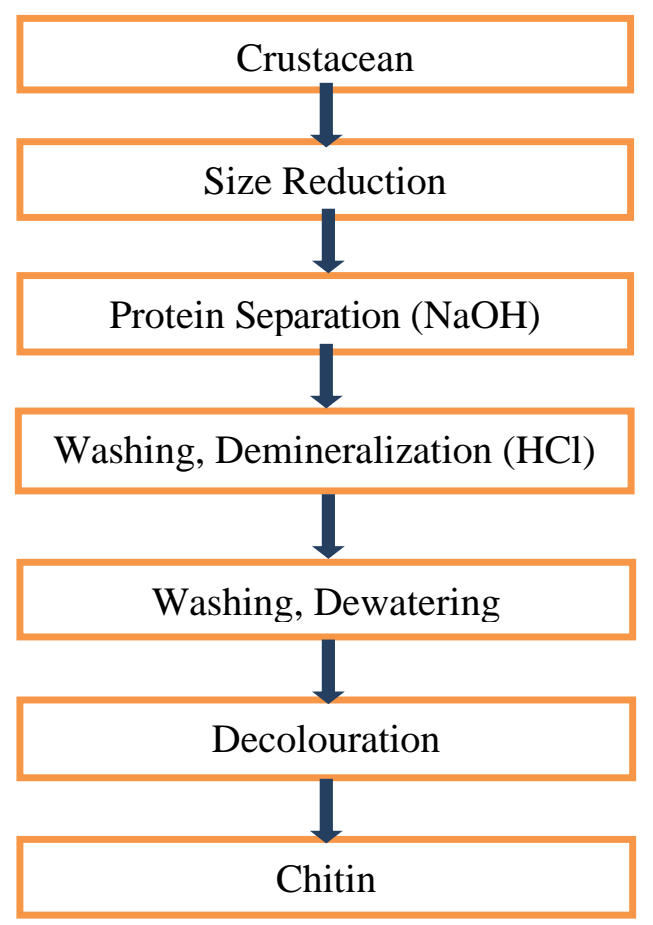

Figure 11: Flowchart for Preparation of Chitin

\section{CHITOSAN}

Chitosan from crustacean chitin: Out of the several sources chitosan, the most attainment sources of chitin are the waste produced during the processing of shellfish and marine crustaceans, like shrimp, crab, krill, lobster, squid and oysters. Typically, marine crustacean shells accommodate about 15-40\% chitin (dry weight) along with calcium carbonate and proteins. To isolate chitin from natural resources in addition to calcium carbonate and proteins, other constituents such as mannan, cellulose, glucan, polygalactosamine, including pigments are required to be removed throughout the extraction procedures. Decalcification of samples is usually carried out using dilute hydrochloric acid accompanied by deproteination in dilute aqueous sodium hydroxide solution. The obtained product is decolourized with the aid of $0.5 \% \mathrm{KMnO} 4$ and oxalic acid. Lastly, chitosan can be obtained from chitin using a hot concentrated sodium hydroxide solution for the deacetylation of the chitin ${ }^{98}$ and the preparation is shown in figure 12 .

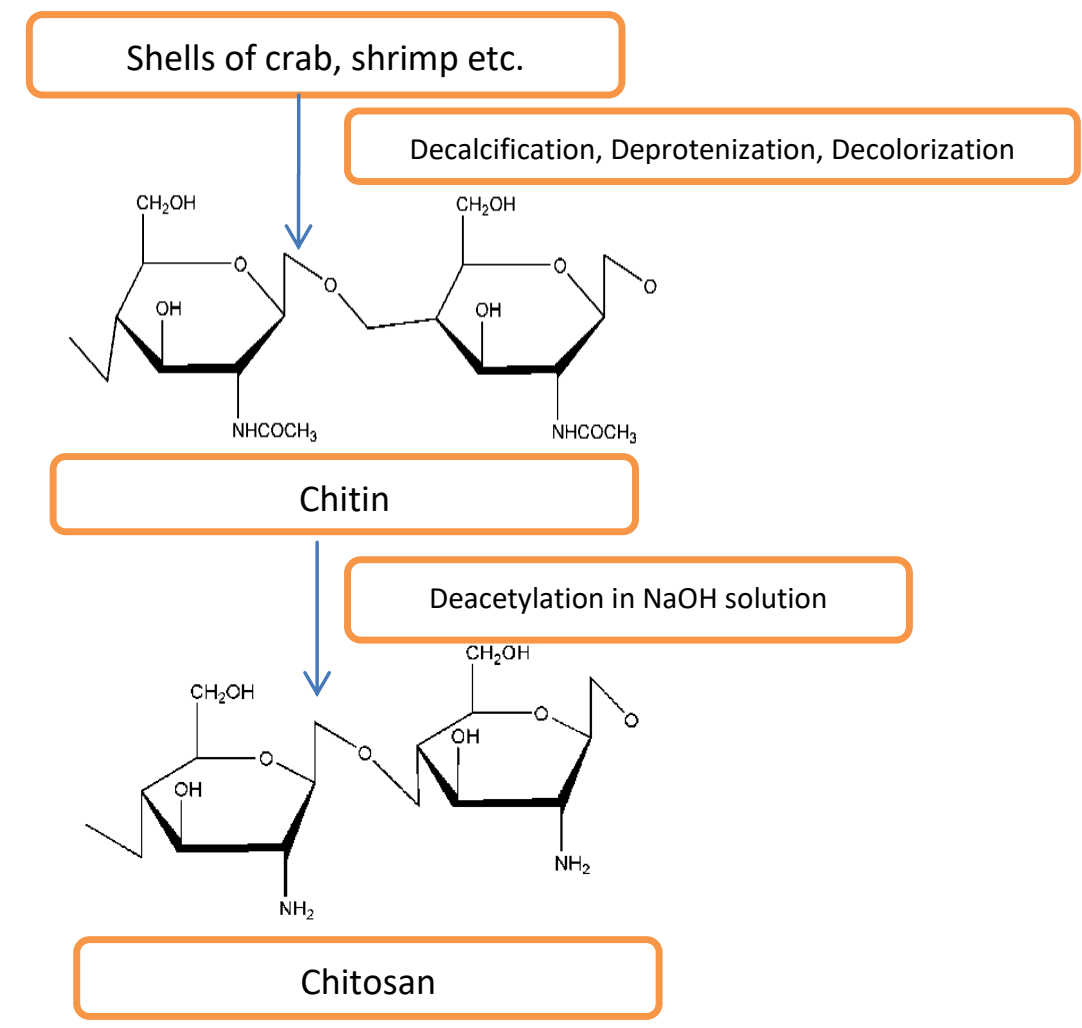

Figure 12: Preparation of chitosan from chitin 


\section{GELATIN}

Sample preparation: Fish samples Carcharhinus amblyrhyncho (shark) and Sphyraena barracuda (Sheela). The fish skin was peeled using a sharp knife and then cleaned with tap water for three times and drained. The skin was stored at $-20^{\circ} \mathrm{C}$ for further extraction and analysis.

Extraction of Gelatin: For further extraction, the fish skins were soaked for 40 minutes in $0.2 \%(\mathrm{w} / \mathrm{v})$ sodium hydroxide and treated with two different acids. Initially with $0.2 \%(\mathrm{v} / \mathrm{v})$ sulphuric acid then with $1 \%(\mathrm{w} / \mathrm{v})$ citric acid solution the extract were treated. Then acid-treated solutions were drained and washed with cold water. The final extraction of gelatin was performed for 18 hours in distilled water at $45^{\circ} \mathrm{C}$. After that by using the freeze-drying method the residual water was removed from the gelatin extract. Finally, the extracts were filtered with the aid of two layers of clothes and evaporated at $70^{\circ} \mathrm{C}$ to remove the extra water from the gelatin extract. The filtrate was then dried in a hot-air oven at $50^{\circ} \mathrm{C}$ and the total yield of Gelatin was calculated as a percentage. 99

Yield of Gelatin $(\%)=\frac{\text { Dry Weight of Gelatin }}{\text { Wet Weight of Gelatin }} \times 100 \%$

\section{DEXTRAN}

It is a type of polysaccharide which is produced by allowing the growth of the bacterium Leuconostoc mesenteroides in a sucrose medium where the bacterium releases an enzyme that can convert sucrose dextran. The product appears as a slime that clogs the pipes and filters thereby interferes with crystallization in the sugar industry. The reaction involved in this process is given in the following equation. 100

n sucrose Dextran-sucrase $n\left(\right.$ glucose- $\left.\mathrm{H}_{2} \mathrm{O}\right)+\mathrm{n}$ fructose

\section{ROLE OF POLYMERS IN PHARMACEUTICAL DRUG DELIVERY}

\section{> IMMEDIATE RELEASE DOSAGE FORMS}

- Tablets: Polymers like microcrystalline cellulose can be used as diluents instead of carbohydrates in tablet formulations of low-dose highly potent drugs. 46 Polyvinyl-pyrrolidone and hydroxypropyl methylcellulose (HPMC) are some polymers that can be used as binders in the formation of granules which improve the flow and compaction properties of tablet formulations before tabletting. 101

- Capsules: The polymeric excipients added to increase the bulk of capsule fills are same as those added in immediate-release tablets. For the preparation of hard (two-piece) and soft (one-piece) capsules, the shell material mostly used is gelatin. Recently another shell material, HPMC has been developed and accepted to use in the manufacturing of hard (two-piece) capsules. ${ }^{102}$

> MODIFIED-RELEASE DOSAGE FORMS: To obtain gastro retention, mucoadhesive and low-density polymers have been studied, with limited success so far, for their capability to prolong the gastric residence time by forming a bond with the mucus lining of the stomach and floating on the surface of the gastric contents. 103

$>$ EXTENDED-RELEASE DOSAGE FORMS: Extended and sustained release dosage forms extent the release rate of the drug to maintain time the drug level within the therapeutic range and thus reduces the dosing frequency which increases the patient compliance. Commonly used water-insoluble polymers for extended-release applications are ammonium methacrylate copolymers, cellulose acetate, cellulose derivatives and polyvinyl derivative, polyvinyl acetate. 104

> GASTRORETENTIVE DOSAGE FORMS: For obtaining the extended-release of a drug, gastro retentive dosage forms are more suitable. In this system, the formulation will remain for a longer duration of time in the stomach from where the drug release in situ and get dissolve in the liquid contents of the body, which passes slowly into the small intestine. 105

\section{APPLICATION OF NATURAL POLYMER IN DRUG DELIVERY SYSTEM}

$>$ COLON DELIVERY: Degraded by microflora present in the human colon which supports colon drug delivery. Coating material should have a satisfying film-forming property and mucoadhesive property. Microspheres for colon delivery developed. Ciofani et al (2008) developed an alginate-based drug delivery system for neurological applications, precisely, by taking into consideration of the target application of neural regeneration and neuroprotection. 106

$>$ TOPICAL DELIVERY: A family member of sulfated polysaccharides, carrageenans are isolated from red marine algae are widely used in the industry because they can mold into stiff and thermo reversible gels.

> OCULAR DELIVERY: Ocular bandage lenses are prepared from chitosan due to its excellent film capability.

$>$ MUCOSAL DELIVERY: Natural polymer is used to formulate bioadhesive dosage forms as it gets protonated in acidic solution and binds strongly to negatively charged cell surface that makes it useful.

> TRANSDERMAL DRUG DELIVERY: Several studies were performed on propranolol hydrochloride delivery systems with various natural polymer possessing distinctive crosslink densities as control drug release membranes and chitosan gel as a drug reservoir.

> GENE DELIVERY: Some natural polymer especially shell of shrimp produce nanoparticles by reacting with DNA which is likely to taken by the body. 107

\section{CONCLUSION}

Biopolymers which are obtained from the animal sources have gathered great attention in the pharmaceuticals due to their uses in the fields related to new drug delivery systems and the maintenance of physical health. Animal sources biopolymers are very much preferable over synthetic polymers as they are nontoxic, facilely available at low cost, utilized in low concentration, and are naturally extracted to provide a nutritional supplement. Animal sources biopolymers increase the drug release rate from the tablet and decrease the dissolution and disintegration time, and they are used as binder super-disintegrant and diluent. In the manufacturing of drugs, the choice of right polymer is important, as, for delivery of the drug, polymers play a crucial role. The selection of polymers has to be taken appropriately considering its drug compatibility, degradation pattern and toxicity. Thus, we can say that the polymers obtained from natural sources can act as a good alternative for synthetic polymers by overcoming various side effects of synthetic polymers. Nowadays, conventional polymers are replaced by bio-based polymers as their applications polymers are vast from commodity to hi-tech tool due to their progress in biotechnologies and public awareness. It can be concluded that natural polymers and their modified derivatives are very promising candidates for the mucosal, colonic and different targeted protein/peptide, gene/vaccine, 
and anticancer drug delivery. Still, some stumbling blocks hinder its commercialization.

\section{REFERENCES}

1. Gopalrao $\mathrm{M}$, Bharathi $\mathrm{P}$, Akila RM, "A comprehensive review on biopolymers" SRCC, 2014; 4(2):61-68.

2. Kaushik K, Sharma RB, Agarwal S, "Natural Polymers and their Applications" Int J Pharm Sci Rev Res, 2016; 37(2):30-36.

3. Saripilli R, Teella P, Navya S, Swain RP et al., "Natural polymers: a recent review" WJPPS, 2017; 6(8):472-494.

4. Ananthakumar R, Chitra K, Satheshkumar S, "A review on applications of natural polymers in gastroretentive drug delivery system" Drug Invent, 2018; 10(3):285-218.

5. Kalia S, Averous L, "Biopolymers: Biomedical and Environmental Applications. $1^{\text {st }}$ ed. Salem: Wiley-Scrivener; 2010. P. 559-574.

6. Jana S, Gandhi A, Sen KK, Basu SK, "Natural Polymers and their Application in Drug Delivery and Biomedical Field" JPST, 2011; 1(1):16-27.

7. Thomas B. Goudoulas, "Polymers and Biopolymers as Drug Delivery Systems in Nanomedicine" Recent Pat Nanotechnol, 2012; 2:52-61.

8. Jae YJ, Se-KK, “Chitosan as Potential Marine Nutraceutical” Adv Food Nutr Res, 2012; 65:122-132.

9. Casparus J, Reinhard V, "Products and applications of biopolymers" Intech, 2012; 6(2):1-201.

10. Singh AV, "Biopolymers in Drug Delivery: A Review" Pharmacologyonline, 2011; 1:666-674.

11. Sevda SE, Susan JM. "Potential applications of chitosan in veterinary medicine" Adv Drug Deliv Rev, 2004; 56(2):14671480.

12. Basel Y, "Classification, characterization, and the production processes of biopolymers used in the textiles industry" J Text Inst, 2016; 10(3):1754-2340.

13. Jane GT, David AT, "Synthesis of biopolymers: proteins, polyesters, polysaccharides and polynucleotides" Curr Opin Solid State Mater Sci, 1996; 1:407-411.

14. Jency G, Jegan SR, Mahija SP, "Collagen and Its Therapeutical Applications in Regenerative Medicine" IJSRD, 2018; 6(1): 23212613.

15. Krushnakumar J, Gandhi S, Deshmane V, Kailash RB, "Polymers in pharmaceutical drug delivery system" IJPSR, 2012; 14(2):5766.

16. Sreeraj G, Augustine A, Sabu T, "Effective Drug Delivery System of Biopolymers Based On Nanomaterials and Hydrogels - A Review" Drug Des, 2016; 5(2):2-7.

17. Dutta PK, Dutta J, Tripathi VS, "Chitin Chitosan: Chemistry Property and Application" JSIR, 2004; 63:20-31.

18. Yadav P, Yada H, Shah GV et al, "Biomedical Biopolymers, their Origin and Evolution in Biomedical Sciences: A Systematic Review" JCDR, 2015; 9(9):21-25.

19. Hamed N, Samiramis P, Esmaeel S, "A Review on Some Natural Biopolymers and Their Applications in Angiogenesis and Tissue Engineering" JAB, 2018; 5(3):81-91.

20. IslemY, Marguerite R, "Chitin and Chitosan Preparation from Marine Sources. Structure.Properties and Applications" Mar drugs, 2015; 13:1133-1174.

21. Hengameh H, Mehdi B, "Applications of biopolymers I: chitosan" Monatsh Chem, 2009; 140:1403-1420.

22. Lakshmana PS, Suriyaprakash TNK, "Role of Natural Polymers in Drug Delivery Systems as Challenging Ailments" Nov Appro Drug Des Dev, 2017; 3(1):1-3.

23. Daniel EAK, Michael RH, "Chitin and Chitosan: Production and Application of Versatile Biomedical Nanomaterials" Int J Adv Res, 2016; 4(3):411-427.

24. Shigehiro $\mathrm{H}$, "Chitin and chitosan as novel biotechnological Materials" Polym Int, 1999; 48:732-734.

25. Deming TJ, Fournier MJ, Mason TL, Tirrell DA, "Structural modification of a periodic polypeptide through biosynthetic replacement of proline with azetidine-2-cerboxylic acid" Macromol, 1996; 29(4):1442-1 444.

26. Laura GRB, Mirna LSA, "Collagen: A review on its sources and potential cosmetic Applications" J Cosmet Dermatol, 2018; 17:20-26.

27. Babu RP, Connor KO, Ramakrishna S, "Current progress on biobased polymers and their future trends" Prog Biomater, 2013; 2(8):1-16.
28. Chak V, Kumar D, Sharad V, "A Review on Collagen Based Drug Delivery Systems" IJPTP, 2013; 4(4):811-820.

29. Saripilli R, Teella $P$, Navya $S$ et al., "Natural polymers: a recent review" WJPPS, 2017; 6(8):472-494.

30. Maytal F, Meital Z, "Drug delivery from gelatin-based systems" Expert Opin Drug Deliv, 2015; 12(9):1547-1563.

31. Kamrun N, Hossain K, Khan TA, "Alginate and Its Versatile Application in Drug Deliv" JPSR, 2017; 9(5): 606-617.

32. Joby J, Jozef TH, Sabu T, Sreeraj G, "Biopolymer based nanomaterials in drug delivery systems: A review" Mater Today Chem, 2018; 9:43-45.

33. Sharma KA, "Biopolymers in Drug Delivery" Biopolymers Res, 2017; 1(1):1-3.

34. Abdulsalam A, Nafaa A, Marwan A, "Xanthan gum; Its Biopharmaceutical Applications: An Overview" WJPPS, 2017; 7(1):1536-1548.

35. Chun YH, Jen MK, Shu JW, Hsing TT, "Isolation and characterization of fish scale collagen from tilapia (Oreochromis sp.) by a novel extrusion hydro-extraction process" Food Chem, 2016; 190:997-1006.

36. Maytal F, Meital Z, "Drug delivery from gelatin-based systems" Expert Opin Drug Deliv, 2015; 6(2):742-5247.

37. Patil GV, "Biopolymer Albumin for Diagnosis and In Drug Delivery" Drug Development Research, 2003; 58:219-247.

38. Faiza A, Wafa A, Mayson HA, "Biopolymers and Drug Delivery Systems" Polym Sci, 2017; 3(4):2471-9935.

39. Gómez-Guillén MC, Giménez B,Montero P, "Extraction of Gelatin From Fish Skins By High Pressure Treatment" IJPTP, 2017;7(1):1536-1548.

40. Devi A, Kamatchi P, LeelaK, "Extraction, Characterization and Application of Gelatin from Carcharhinus Amblyrhynchos and Sphyraena barracuda" JBB, 2016; 2(6):40-49.

41. Yadav P, Yadav H, Shah GV, Shah G, Dhaka G, "Biomedical Biopolymers, their Origin and Evolution in Biomedical Sciences: A Systematic Review" JCDR, 2015; 9(9):21-25.

42. Kulkarni VS, Butte KD, Rathod SS, "Natural Polymers - A Comprehensive Review" IJRPBS, 2012; 3(4):2229-3701.

43. Thomas BG, "Polymers and Biopolymers as Drug Delivery Systems in Nanomedicine" Recent Patents on Nanomedicine, 2012; 2:52-61.

44. Luca GJFM, Rui LR, "Natural polymers for the microencapsulation of cells" J R Soc Interface, 2014; 2(6):40-49.

45. Alam T, Parvez N, Kumar SP, "FDA-Approved Natural Polymers for Fast Dissolving Tablets" J Pharma, 2104; 3(4):1-6.

46. Azharuddin M, Danakka S, Krishnananda K, "Formulation and evaluation of fast disintegrating tablets of Granisetron $\mathrm{HCl}$ using natural polymers" Res Pharm, 2011; 1(2):20-27.

47. Scott AS, Patricia S. Wolfe, KG, Jennifer MM, Isaac A. Rodriguez L, Gary L. B, "The Use of Natural Polymers in Tissue Engineering: A Focus on Electrospun Extracellular Matrix Analogues" Polym, 2010; 2:522-553.

48. Islem Y, Marguerite R, "Chitin and Chitosan Preparation from Marine Sources. Structure.Properties and Applications" Mar Drugs, 2015; 13:1133-1174

49. Babak G, Hadi A, "Biodegradable Polymers" InTech, 2013; 3(4):143-177.

50. Sahithi B, Ansari SK, Hameeda SK, "A Review on Collagen Based Drug Delivery Systems" IJRPB, 2013; 1(3):461-468.

51. Jagdale SC, Patil SA, Kuchekar BS, "Design, development and evaluation of floating tablets of tapentadol hydrochloride using chitosan" AJPCR, 2012; 5(4):163-168.

52. Ki-Won S, Yong-Seok K, Gap-Shik C, "Rheology of concentrated xanthan gum solutions: Steady shear flow behaviour" Fibers Polym, 2006; 7(2):129-138.

53. Sandolo C, Coviello T, Matricardi P,Alhaique F, "Characterization of polysaccharide hydrogels for modified drug delivery" Eur Biophys J, 2007; 36(7):693-700.

54. Santos H, Veiga F, Pina ME, Sousa JJ, "Compaction, compression and drug release properties of diclofenac sodium and ibuprofen pellets comprising xanthan gum as a sustained release agent" IJP, 2005; 295:15-27.

55. Sharma BR, Naresh L, Dhuldhoya NC, Merchant SU, Merchant UC, "Xanthan gum - A boon to food industry" Food Promotion Chronicle, 2006; 1(5):27-30.

56. Vishakha K, Kishor B, Sudha R, "Natural polymers - a comprehensive review" IJRPBS, 2012; 3(4):1597-1613.

57. Wang F, Wang YJ. Sun Z, "Conformational role of xanthan in its interaction with locust bean gum" JFS, 2002; 67(7):2609-2614. 
58. Williams P, Clegg S, Day D, Phillips G. Nishinari K, "Mixed gels formed with konjacmannan and xanthan gum" In: Dickinson E, editor. Food polymers, gels and colloids, Cambridge, RSC, 1991; 339-348.

59. Xue D, Sethi R, "Viscoelastic gels of guar and xanthan gum mixtures provide long- term stabilization of iron micro and nanoparticles" J Nanoparticle Res, 2012; 14(11): 1-14.

60. Das D, Goyal A, "Charactrization and biocompatibility of glucan: a safe food additive from probiotic Lactobacillus plantarum DM5" J Sci Food Agric, 2014; 94(4):683-90.

61. Naessens M, Cerdobbel AN, Soetaert W, Vandamme EJ, "Leuconostoc dextran sucrase and dextran: production, properties and applications" JCTB, 2005; 80(8):845-60.

62. Patrushev VI, Shekhtman MA, "Role of blood coagulation in the pathogenesis of acute experimental pneumonias" Pathological physiology and general pathology, 1973; 75(5):508-510.

63. Giri SN, Benson J, Siegel DM, Rice SA, Schiedt M, "Effects of pretreatment with anti-inflammatory drugs on ozone-induced lung damage in rats" Proc Soc Exp Biol Med, 1975;150:810-14.

64. Awad HA, Butler DL, Boivin, G.P, "Autologous mesenchymal stem cell-mediated repair of tendon” Tissue Eng, 1999; 5(3):267-277.

65. Bruno FF, Akkara JA, Ayyagari M, Kaplan DL, Gross RS, Swift G, Dordiik JS, "EnxymaUc modifkatlon of Insoluble amylose in organic solvents". Macromol, 1995; 28(7):8881-8883.

66. Bhavani AL, Nisha J, "Dextran-the polysaccharide with versatile uses" IJPBS, 2010; 1(4):569-73.

67. Sam E, LanceIon-Pin C, Ferigo F, Moreau V, Chanzy H, Driguez H, "Phosphorolytic synthesis of cellodextrins". Carbohydr Res, 1995; 27(1):217-226.

68. Raymond S, Henriasat B, Gui DT, Kvick A, Chanxy H, "The crystal structure of methyl beta-cellotrloside monohydrate 0.25 ethanolate and its relatlonship to cellulose II" Carbohydr Res, 1995; 27(7):209-229.

69. Du SM, Wang H, Tse-Din Y-C, Seernan NC, "Topological transformations of synthetic DNA knots" Biochemistry, 1995; 34(2):673-682.

70. Du SM, Stellar BD, Swman NC, "A synthetic DNA molecule in three knotted topologies" J Am Chem Sot, 1995; 117(2):1141200.

71. Kalousek S, Lubitz W, "High-level poly( $\beta$-hydroxybutyrate) production in recombinant Escherichia coli in sugar free, complex medium" Can J Microbial, 1995; 41(4):216-221.

72. Kang CK. Kusaka S, Doi Y, "Structure and properties of poly(3hvdroxybutyrate-co-4-hydroxybutyrate) produced by Alcaligenes Iatus" Biotechnol Lett, 1995;1 7(8):583-588.

73. Archibald SJ, Krarup J, Shefner ST, Madison RD, "A collagenbased nerve guide conduit for peripheral nerve repair: an electrophysiological study of nerve regeneration in rodents and nonhuman primates" J Comp Neurol, 1991; 306(4):685-696.

74. Muller RH, Mader K, Gohla S, "Solid lipid nanoparticles for controlled drug delivery-A review of the state of the art" Eur J Pharm Biopharm, 2000; 50:161-177.

75. Jeyanthi R, Rao KP, "In vivo biocompatibility of collagen poly (hydroxyethyl methacrylate) hydrogels" Biomaterials, 1990; 1:238-243.

76. Woerly S, Maghami G, Duncan R, "Synthetic polymer derivatives as substrata for neuronal adhesion and growth" Brain Res Bull, 1993; 30:415-422.

77. Maeda M, Tani S, Sano A, Fujioka K, "Microstructure and release characteristics of the minipellet, a collagen based drug delivery system for controlled release of protein drugs" J Control Release, 1999; 62:313-24.

78. Yang SC, Lu LF, Cai Y, Zhu JB, Liang BW, Yang CZ, "Body distribution in mice of intravenously injected camptothecin solid lipid nanoparticles and targeting effect on brain" J Control Release, 1999; 59:299-307.

79. Koyama N, Dci Y, "Continuous production of poly(3 hydroxybutyrate-co-3-hydroxyvalerate) by Alcaligenes eutrophus" Biotechnol Lett, 1995; 17(6):281-204.

80. Dutta P K, Khatua M K, Dutta J, Prasad R, "Use of ChitosanDMAc/LiCl gel as drug carriers" Int J Chem Sci, 2003; 1(2):93102.

81. Dutta PK, DuttaJ, Tripathi VS, "Chitin and chitosan: Chemistry, properties and applications" JSIR, 2004; 63:20-31.
82. Becker DE, DDS, "Antithrombotic Drugs: Pharmacology and Implications for Dental Practice" Anesth Prog, 2013; 60(2):7280.

83. Lee M, Nah JW, Kwon Y, Koh JJ, Ko KS, "Water-soluble and low molecular weight chitosan-based plasmid DNA delivery" Pharm Res, 2001; 18(4):427-431.

84. Lee D, Zhang W, Shirley SA, Kong X, Hellermann GR, "Thiolated chitosan/DNA nanocomplexes exhibit enhanced and sustained gene delivery" Pharm Res, 2007; 24(1):157-167.

85. Doi Y, "Microbial synthesis, physical properties, and biodegradabillty of polyhydroxyalkanoates" Macromol Symposia, 1995; 99(12):565-599.

86. Kato Y, Onishi H, Machida Y, "Application of chitin and chitosan derivatives in the pharmaceutical field" Curr Pharm Biotechnol, 2003; 4(5):303-309.

87. Rinaudo M, "Chitin and chitosan: Properties and applications" Prog Polym Sci, 2006; 31:603-632.

88. Atala A, Bauer S.B, Soker S, James J.Y, "Alan B. Retik.Tissueengineered autologous bladders for patients needing cystoplasty" Lancet, 2006; 367(23):1241-1246.

89. Tungtong $\mathrm{S}$, Okonogi $\mathrm{S}$, Chowwanapoonpohn S, Phutdhawong $\mathrm{W}$, Yotsawimonwat S, "Solubility, viscosity and rheological properties of water-soluble chitosan derivatives" MaejoInt J Sci Technol, 2012; 6(2):315-322.

90. Pillai CKS, Paul W, Sharma CP, "Chitin and chitosan polymers: Chemistry, solubility and fiber formation” Prog Polym Sci, 2009, 34:641-678.

91. Rodrigues A, Emeje M, "Recent applications of starch derivatives in nanodrug delivery" Carbohydr Polym, 2012; 87:987-994.

92. Quinlan GJ, Martin GS, Evans TW, "Albumin: Biochemical Properties and Therapeutic Potential". Hepatology, 2005 41(6):1211-1219.

93. Reddy N, Yang $\mathrm{Y}$, "Potential of plant proteins for medical applications" Trends Biotechnol, 2011; 29(10):490-498.

94. Lai LF, Guo HX, "Preparation of new 5-fluorouracil-loaded zein nanoparticles for liver targeting" Int J of Pharm, 2011; 404(1 2):317-323.

95. Lee S, Alwahab NS, Moazzam ZM, "Zein-based oral drug delivery system targeting activated macrophages" Int J Pharm, 2013; 454(1):388-393.

96. Nagal A, Singla AK, "Applications of Silk in Drug Delivery: Advancement in Pharmaceutical Dosage Forms" Indo Global J Pharma Sci, 2013; 3(3):204-211.

97. Numata K, Kaplan DL, "Silk-based delivery systems of bioactive molecules" Adv Drug Deliv Rev.2010; 62(15):1497-1508.

98. Elzoghby AO, Samy WM, Elgindy NA, "Protein-based nanocarriers as promising drug and gene delivery systems" J Control Release, 2012; 161(1):38-49.

99. Shoulders MD, Raines RT, "Collagen Structure and stability" Annu Rev Biochem, 2009; 78:929-958.

100. Jha N, "Microbial Polysaccharides: Appication, Production and Features". Available at: https://www.biologydiscussion.com/biotechnology/microbialpolysaccharides-application-production-and-features/10412

101. Iglesias N, Galbis E, Romero-Azogil L, Benito E, Lucas R Gracia M, Violante de-Paz M, "In-Depth Study into Polymeric Materials in Low-Density Gastro-retentive Formulations" Pharmaceutics, 2020; 12:636-680.

102. Hadi MA, Rao NGR, Avanapu AR, Shiva G, Akram JW "Impact of capsules as a carrier for multiple unit drug delivery and the importance of HPMC capsules" RJPT, 2013; 6(1):34-43.

103. Singh D, Chaturvedi S, Agarwal V, Kumari P, "Approaches to increase the gastric residence time: Floating drug delivery systems- A review" AJPCR, 2010; 5:525-532.

104. Agarwal G, Agarwal S, Karar PK, Goyal S, "Oral Sustained Release Tablets: An Overview with a special emphasis on Matrix Tablet" Am J Adv Drug Deliv, 2017; 5:1-13.

105. Pawar VK, Kansal K, Garg G, Rajendra A, Singodia, Kulkarni G, "Gastroretentive dosage forms: A review with special emphasis on floating drug delivery systems" Drug Deliv, 2011; 18(2):97110.

106. Rajpurohit H, Sharma P, Bhandari A, "Polymers for Colon Targeted Drug Delivery" IJPS, 2010; 72(6):689-696.

107. Elieh-Ali-Komi D, Hamblin R, "Chitin and Chitosan: Production and Application of Versatile Biomedical Nanoparticles" IJAR, 2016; 4(3):411-427. 